\title{
Connecting with Clients: Assessing Clients Preference of Counsellor
}

Salina Nen, Nasrudin Subhi, Najwa Afiqa Rohaizad \& Haikal Anuar Adnan

To Link this Article: http://dx.doi.org/10.6007/IJARBSS/v12-i1/12107

DOI:10.6007/IJARBSS/v12-i1/12107

Received: 09 November 2021, Revised: 10 December 2021, Accepted: 25 December 2021

Published Online: 16 January 2022

In-Text Citation: (Nen et al., 2022)

To Cite this Article: Nen, S., Subhi, N., Rohaizad, N. A., \& Adnan, H. A. (2022). Connecting with Clients: Assessing Clients Preference of Counsellor. International Journal of Academic Research in Business and Social Sciences, 12(1), 878-888.

Copyright: @ 2022 The Author(s)

Published by Human Resource Management Academic Research Society (www.hrmars.com)

This article is published under the Creative Commons Attribution (CC BY 4.0) license. Anyone may reproduce, distribute, translate and create derivative works of this article (for both commercial and non0-commercial purposes), subject to full attribution to the original publication and authors. The full terms of this license may be seen at: http://creativecommons.org/licences/by/4.0/legalcode

Vol. 12, No. 1, 2022, Pg. $878-888$

Full Terms \& Conditions of access and use can be found at http://hrmars.com/index.php/pages/detail/publication-ethics 


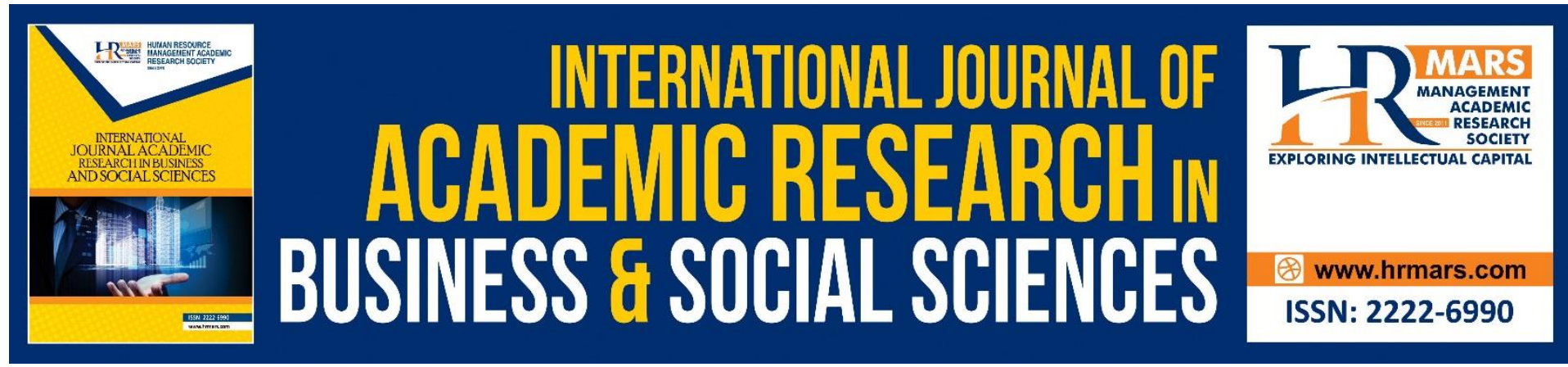

\title{
Connecting with Clients: Assessing Clients Preference of Counsellor
}

\section{Salina Nen, Nasrudin Subhi, Najwa Afiqa Rohaizad \& Haikal Anuar Adnan}

Center for Research in Psychology and Human Well-Being, Faculty of Social Science and Humanities, Universiti Kebangsaan Malaysia, 43600 Bangi, Selangor, Malaysia

Corresponding Author: salina.nen@ukm.edu.my

\begin{abstract}
Counsellor characteristics influence the effectiveness of counselling process. Counsellor characteristics have a greater impact than the theoretical orientation of counselling sessions. Understanding how these factors interact and influence one another can assist in improving the overall quality of counselling services. The primary objective of this study was to elicit clients' perspectives on the characteristics they believe counsellors should possess. Additionally, we will examine issues relating to counselling and initiatives to seek counselling services, whether voluntary or not. This study employs a quantitative approach. Participants demographic information such as race, year of study, level of education, issues referred, and counselling initiatives was gathered via questionnaire. Participants were also surveyed regarding the significance of the counsellor's personal and professional characteristics. This questionnaire was completed voluntarily by 44 participants. Following the counselling session, participants complete a questionnaire. The findings indicated that family and university-related issues (career, learning, adjustment, and assignments) became the most frequently discussed topics during counselling sessions. In comparison, anxiety and depression are the most frequently referred mental health issues to counsellors. Counsellors who are trustworthy, sincere, honest, know how to build rapport, and empathic are at the top of the participants' five (5) list of required characteristics. On the other hand, same-sexgender relationships and religious beliefs are not critical determinants. This study sheds new light on counselling issues that are frequently brought up by clients, particularly in higher education institutions. The most critical highlight is the importance of counsellors to arm themselves with the necessary attitudes that clients readily accept.
\end{abstract}

Keywords: Counselling, Counsellors Characteristics, Client's Preferences, Therapy, Therapist

\section{Introduction}

Counselling services are professional help that offers numerous benefits. The value of counselling services is demonstrated by the establishment of counselling units in a variety of large organisations, including government agencies, private businesses, non-governmental organisations (NGOs), schools, institutions of higher learning, and even religious organisations. Individuals who receive counselling services benefit more than those who do 
not receive similar services (Lohan et al., 2021). Counselling has been shown to be effective in the treatment of a variety of individual problems, including depression, anxiety, marital conflict, substance abuse, health problems, and sexual problems, as well as with a variety of populations within society, including children, adolescents, adults, and the elderly (Larsen et al., 2020; Cosci et al., 2020). Counselling utilises cognitive, emotional, and behavioural or systemic intervention strategies to promote mental health, psychological well-being, and human growth and career development. Counsellors who work with clients in accordance with these principles strive to support them in achieving optimal psychosocial functioning by assisting clients in resolving problematic behavioural patterns, preventing, rehabilitating, and improving their quality of life.

Counselling effectiveness is contingent upon a variety of factors, including the theory employed, the counsellor's abilities, the client's characteristics, and the counsellor. Each client has their own perspective on what constitutes a significant event during a counselling session. What is critical are the client's perceptions of the counsellor's personal and professional characteristics. Previous research has demonstrated that factors such as the theory employed make no significant difference in determining the effectiveness of counselling sessions (Wampold, 2001, 2007, 2010). On the other hand, regardless of the approach used by counsellors, counsellors' characteristics are critical in determining the impact of the counselling process (Wampold, 2006; Delgadillo, 2020). For instance, a study conducted by Kim et al (2006) discovered no difference in the effectiveness of counselling between therapists who used Cognitive Behavioral theory and therapists who used Interpersonal Psychotherapy. Additionally, their study demonstrated that, despite using the same approach, effectiveness varied, with some therapists being more effective than others. McKay et al (2006) reported surprising study findings that therapists who met with their clients frequently and administered a placebo reported greater efficacy than therapists who administered antidepressant medications.

According to previous research, at least 14 therapist/counsellor characteristics have been identified (Anderson et al., 2009; Baldwin et al., 2007; Duncan et al., 2010; Lambert et al., 2005; Norcross, 2011; Wampold, 2007). Effective therapists possess strong interpersonal skills, including language fluency, positive interpersonal relationships, and the ability to demonstrate affection, expressiveness, friendliness, acceptance, empathy, and a focus on others. Additionally, clients believe that competent therapists make clients feel understood, are trustworthy to assist, work with a variety of clients, show high acceptance, provide realistic solutions, have common values, culture, attitudes, and worldview, and prioritise the client's interests. Other characteristics including ability to persuade/influence, convince, and monitor client progress is mentioned, as is flexibility; an openness to discussing serious issues; the ability to instill confidence and hope in clients; sensitivity to cultural diversity; sensitivity to one's own values; and an ongoing desire to improve oneself. Counsellor characteristics are frequently classified into two broad categories: personal characteristics and professional characteristics. Professional characteristics refer to the knowledge, abilities, theoretical orientation, and experience that can assist counsellors in reaffirming their identity and professional values in their community/market. In comparison, personal characteristics refer to an individual's inner characteristics. Both professional and personal characteristics have a significant impact on the therapeutic outcome. 
There are still a dearth of local studies examining the characteristics of effective counsellors from the client's perspective. However, comparable studies conducted in other countries have advanced to a greater level by examining counselling process from both the client and counsellor perspectives (Sackett et al., 2012; Råbu \& Moltu, 2021). Thus, it is pertinent for this study to look at the characteristics of counsellors that clients believe are necessary. Client expectations regarding desired characteristics may differ from those of the counsellor providing the services. Having information about the characteristics of counsellors involved in the counselling process undoubtedly helps raise counsellors' and counsellor educators' awareness of the importance of providing more efficient, competitive, and effective counselling.

\section{Methodology Research Design}

This study uses a quantitative study design with a questionnaire to collect and analyse data. The online questionnaire was distributed to all clients who had completed a counselling session at the Faculty of Social Sciences and Humanities' Psychology and Counselling Wellness Specialist Center (PKPK). At an early stage, the counsellor trainee was provided with a detailed description of the questionnaire's objectives. The counsellor trainee was then sent a link to a questionnaire via a google form. This link is shared with students via a WhatsApp group and also via email. Clients are not obligated to complete this survey. This questionnaire is selfadministered. This questionnaire was to be completed by the counsellor trainee only after the client had completed the counselling session. In lieu of the more traditional method of distribution, Google Form was chosen as the primary medium for distributing the questionnaires because most clients have smartphones, email addresses, and internet access. The online form enables clients to respond to the questionnaire using their smartphones or computers.

The questionnaire is divided into three sections, A, B, and C. Section A collects demographic information about clients, such as their age, year of study, the issues for which they sought counselling, referral initiatives, and race. Part B contains a list of sixteen characteristics of counsellors: integrity, neat appearance, sincerity, honesty, problem-solving abilities, liked, the friendly, trustworthy, experienced, sociable, adaptable, same faith, same gender, empathy, multicultural competence, and relationship building abilities. Clients are required to complete all these sections, and the response options are in the Likert scale, which ranges from very important to important to neutral to not important. This list of characteristics was compiled using literature reviews and relevant field experts (Corey, 2009; Sacket et al., 2012; Wampold, 2007; Bhargava \& Sriram, 2016; Gladding, 2015).

\section{Survey}

This study's questionnaire consists of three sections, A, B, and C. Section A focuses on client demographic data such as age, race, year of study, highest level of education, initiative to seek counselling services (volunteer or referred), and issues that prompted the referral for counselling. Section B focuses on counsellors' personal and professional characteristics. Counsellors and clients are asked to rate the importance of fifteen different personal and professional characteristics. The client is provided with a list of possible responses in the Likert format, which includes very important, important, neutral, and not important. Section C consists of open-ended questions in which clients are asked about their counselling session 
experiences. Sections A and B consist of multiple-choice questions, whereas Section C is an open-ended questionnaire. However, this article focuses exclusively on the analysis of data findings for Parts $A$ and $B$.

\section{Participants}

All participants in this study received counselling services from the Psychological Well Being and Counselling Specialist Center (PKPK), Faculty of Social Sciences and Humanities. Most participants were the National University of Malaysia students from various faculties, with a small number of participants were from other places. A total of 44 clients completed the questionnaires distributed. The clients in this study ranged in age from 20 to 40 years. Please refer to Tables 1 and 2 for details on the study participants demographics.

\section{Data Collection and Analysis}

After the client completed the counselling session, the data collection process began. The counsellor provided the client with a link to a google form or a survey form to complete. As previously stated, client participation in this study was voluntary. The data from Sections A and $B$ were then analysed using a simple descriptive method.

\section{Results and Discussion}

\section{Demographic Data}

The majority of 95.5 percent of participants are between the ages of 20 and 25 . Simultaneously, the remaining 2.3 percent are between the ages of 26-30 and 36-40. Most participants are Malays (68.2 percent), followed by Chinese (20.5\%) Indians (9.1\%), and Bumiputera Sabah and Sarawak (2.3\%). Following data indicates the participants year of study. According to the study's findings, most participants are university students. Participants comprised 93.2 percent of year three students, 4.5 percent of external clients, and 2.3 percent of year one students. Most participants in the study were college students as the data collected by counsellor trainees whose clients are primarily university students, with a small percentage of external clients or clients from diverse demographic backgrounds. Please refer to Table 1 for details. 
Table 1: Age, Race and Year of Study

\begin{tabular}{|c|c|c|}
\hline Demographic & Number & Percentage (\%) \\
\hline \multicolumn{3}{|l|}{ Age } \\
\hline 20-25 year old & 42 & 95.5 \\
\hline 26-30 year old & 1 & 2.3 \\
\hline 31-35 year old & 0 & 0 \\
\hline $36-40$ year old & 1 & 2.3 \\
\hline Total & 44 & 100 \\
\hline Race & Number & Percentage (\%) \\
\hline Malay & 30 & 68.2 \\
\hline Chinese & 9 & 20.5 \\
\hline Indian & 4 & 9.1 \\
\hline Bumiputera Sabah Sarawak & 1 & 2.3 \\
\hline Total & 44 & 100 \\
\hline Year of Study & Number & Percentage (\%) \\
\hline Year 1 & 1 & 2.3 \\
\hline Year 2 & 0 & 0 \\
\hline Year 3 & 42 & 93.2 \\
\hline Others & 2 & 4.5 \\
\hline Total & 44 & 100 \\
\hline
\end{tabular}

\section{Participants Issues}

Part B discusses the reasons for which study participants seek counselling services. In Section $B$, participants may select more than one response. Additional responses are necessary because the client's issues are diverse and may not be limited to one. Of the total client responses, the highest reason for counselling was career concern and family problems, which are 34.1 percent respectively, followed by student-related assignments, which are 29.5 percent. Problems of self-adjustment, self-confidence, and learning accounted for 27.3 percent, respectively. Anxiety problems accounted for 22.7 percent of cases, time management and romantic relationships accounted for 18.2 percent, academic performance accounted for 15.9 percent of cases, depression and financial issues accounted for 6.8 percent, sleep problems 4.5 percent. In contrast, academic stress, problem in choosing a course, trauma, and suicidal ideas accounted for 1 percent of reported issues. Table 2 details a list of issues reported by the participants. 
Table 2: Personal Issues Reported by the Participants

\begin{tabular}{lcc}
\hline \multicolumn{1}{c}{ Issue } & Frequency & Percentage \\
\hline Family & 15 & 34.1 \\
Career & 15 & 34.1 \\
Student Assignment & 13 & 29.5 \\
Self Confidence & 12 & 27.3 \\
Learning/Lecture & 12 & 27.3 \\
Adjustment Problem in & 12 & 27.3 \\
University & & \\
Anxiety & 10 & 22.7 \\
Romantic Relationship & 8 & 18.2 \\
Time Management & 8 & 18.2 \\
Academic Achievement & 7 & 15.9 \\
Depression & 3 & 6.8 \\
Financial & 3 & 6.8 \\
Sleep Problem & 2 & 4.5 \\
Academic Pressure & 1 & 2.3 \\
Problem in choosing a & 1 & 2.3 \\
course & & \\
Trauma & 1 & 2.3 \\
Suicidal Ideation & 1 & 2.3 \\
\hline
\end{tabular}

According to the study's findings, the most often reported issues by participants include family, career, student assignments, self-confidence, learning, and anxiety. As mentioned previously, most of the participants in this study were students. The findings of this study corroborate past studies indicating that the pressures faced by students are closely related to student life and transitioning to live away from family (Furr et al., 2001; Eisenberg et al., 2007). The primary reason for student referrals for counselling services was found to be concerns about living as a university student. Participants in this study also acknowledged mental health problems. This study examined anxiety, sadness, insomnia, trauma, and suicidal ideation. Anxiety was the most often reported mental health issue $(22.7 \%)$, followed by depression (6.8\%), insomnia (4.5\%), trauma (2.3\%), and suicidal ideation (2.3\%). These findings corroborate those of Bruffaerts, Mortier, Kiekens, and colleagues (2018). In comparison to antisocial behaviour or substance misuse; depression, anxiety, sleep disorders, trauma, and suicidal ideation are the most prevalent mental health problems among college students. Except for anxiety disorders, individuals in this study reported few instances of mental health problems. Nonetheless, students' mental health concerns must be taken seriously, as prior research has demonstrated that mental health disorders can impair academic functioning, including failure to graduate and low academic performance (Kosidou et al., 2014; Eisenberg et al., 2009; Gunnell et al., 2009; Kessler et al., 1995; Hartley, 2010).

\section{Counselling Initiative}

The vast majority of participants in this study (90.9 percent) seek counselling services as a result of course requirements that require students to participate in face-to-face counselling sessions with counsellors. The remainder, or 6.8 percent, were self-referred, and 2.3 percent were referred by third parties (such as family, friends, employers). For additional details, see Graph 1. 


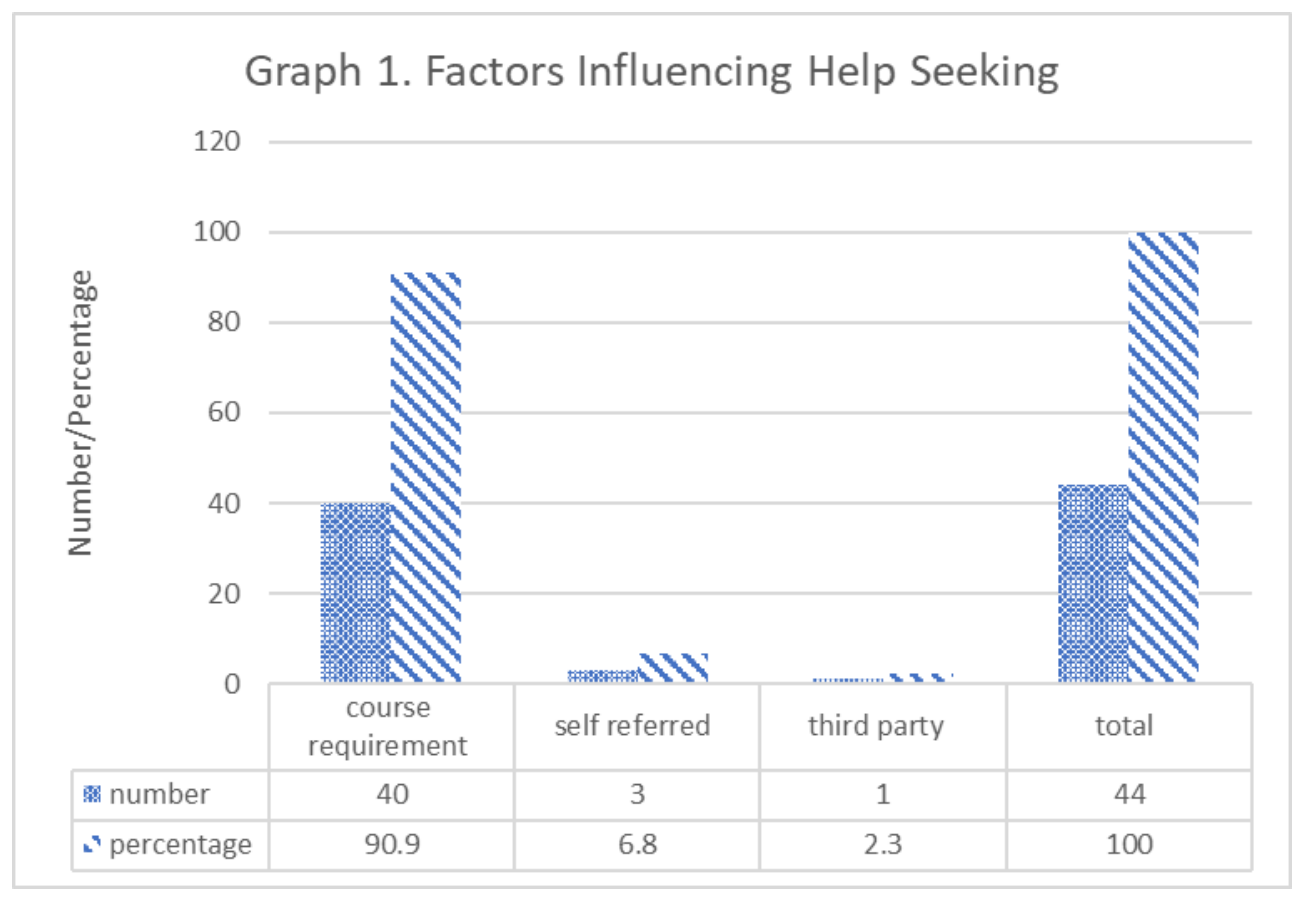

In terms of counselling initiatives, the majority of participants (90.9\%) seek counselling services as a result of course requirements, rather than voluntarily (6.8\%) or as a result of third-party referrals $(2.3 \%)$. The findings corroborate previous studies indicating that university students continue to be wary of and stigmatised by counselling services (Nen \& Ibrahim, 2018; Eisenberg et al., 2011; Mowbray et al., 2006). According to a study conducted by Nen and Ibrahim, students do not reject the value of counselling services (2018). However, stigma and mistrust toward counselling facilities and counsellors obstruct their efficiency. Even when counsellors with experience and training provide counselling services, students are more comfortable discussing problems with family members, friends, and other individuals.

\section{Personal and Professional Characteristics}

The following findings pertain to the personal and professional characteristics of counsellors that are deemed necessary by clients. Most clients rated trustworthiness ( 84 percent), genuine $(77.3 \%)$, honesty (77.3\%), rapport-building skills (70\%) and empathy as the five most important (essential) characteristics (68.2\%). Problem-solving skills (68.2\%), friendliness $(65.9 \%)$, multicultural competence (59\%) and flexibility (59\%) were the next most important characteristics (59\%). While traits like sociable (54.4\%), experienced (54.5\%), likeable $(52.3 \%)$, pleasing appearance (50\%), same faith (48\%), same gender (18.2\%), and funny (13.7\%) ranked lowest in the client's interest assessment chart. 
Table 3: Counsellors Characteristics Preferences

\begin{tabular}{llcccccccc}
\hline No & Characteristics & \multicolumn{2}{l}{$\begin{array}{l}\text { Very } \\
\text { Important }\end{array}$} & \multicolumn{3}{c}{ Important } & Neutral & \multicolumn{2}{c}{$\begin{array}{l}\text { Not } \\
\text { important }\end{array}$} \\
& & No & $\%$ & No & $\%$ & No & $\%$ & No & $\%$ \\
\hline 1 & Funny & 6 & 13.7 & 27 & 61.4 & 8 & 18.1 & 3 & 6.8 \\
2 & Pleasing appearance & 22 & 50 & 22 & 50 & 0 & 0 & 0 & 0 \\
3 & Genuine & 34 & 77.3 & 10 & 27.7 & 0 & 0 & 0 & 0 \\
4 & Honesty & 34 & 77.3 & 10 & 27.7 & 0 & 0 & 0 & 0 \\
5 & Problem-solving skills & 30 & 68.2 & 14 & 31.8 & 0 & 0 & 0 & 0 \\
6 & Likeable & 23 & 52.3 & 16 & 36.3 & 5 & 11.4 & 0 & 0 \\
7 & Friendliness & 29 & 65.9 & 14 & 31.8 & 1 & 2.3 & 0 & 0 \\
8 & Trustworthiness & 37 & 84 & 7 & 15.9 & 0 & 0 & 0 & 0 \\
9 & Experienced & 24 & 54.5 & 19 & 43.2 & 1 & 2.3 & 0 & 0 \\
10 & Sociable & 24 & 54.5 & 18 & 41 & 2 & 4.5 & 0 & 0 \\
11 & Flexibility & 26 & 59 & 18 & 41 & 0 & 0 & 0 & 0 \\
12 & Same faith & 21 & 48 & 12 & 27.2 & 11 & 25 & 0 & 0 \\
13 & Same gender & 8 & 18.2 & 20 & 45 & 13 & 30 & 3 & 6.8 \\
14 & Empathy & 30 & 68.2 & 14 & 31.8 & 0 & 0 & 0 & 0 \\
15 & Multicultural & 26 & 59 & 18 & 41 & 0 & 0 & 0 & 0 \\
& competence & & & & & & & & \\
16 & Rapport-building & 31 & 70 & 13 & 30 & 0 & 0 & 0 & 0 \\
& skills & & & & & & & & \\
\hline
\end{tabular}

According to this study, the top five (5) counsellors characteristics are: trustworthiness (84\%), sincerity (77.3\%), honesty (77.3\%), rapport-building skills (70\%) and empathy (70\%). (70\%). It can be concluded that participants place a higher value on the counsellors' personal characteristics than on their professional ones. Additionally, the survey discovered that participants are unconcerned with counsellors who share their beliefs or are the same gender as them. A counsellor's sense of trust and sincere interest in helping is a vital condition for their effectiveness. These findings corroborate those of Nen and Ibrahim (2018), who discovered that counsellor qualities such as empathy, respect, honesty, friendliness, and a pleasing appearance, as well as being trustworthy, a good listener, and unbiased, influenced the motivation to seek counselling services. Similar effects were discovered in research conducted by (Pope \& Kline, 1999; Ackerman \& Hilsenroth, 2002).

\section{Conclusion}

No single aspect determines the effectiveness of the counselling process. The findings of this study and earlier research demonstrate unequivocally that counselling effectiveness is the consequence of a complex interaction of numerous factors, including counsellors, clients, and theory. The counsellor's traits are one component that influences the process. Counsellors may already possess the requisite personal attributes, but training, education, creativity, experience, and a theoretical orientation will all contribute to a counsellor's increased competence as a professional. It is not necessary for counsellors to possess all the described attributes to be competent counsellors. What is critical is to value existing attributes and to cultivate new ones. The study's findings have implications for educational institutions that train future counsellors. It exposes students to critical components of counsellor education while also emphasising contemporary theory, orientation, and skills. On the other hand, 
prospective counsellors must be acutely aware that their theories, techniques, knowledge, and experience must be compatible with personalities suited to positions requiring extensive connection and involvement with humans.

\section{References}

Ackerman, S. J., \& Hilsenroth, M. J. (2003). A review of therapist characteristics and techniques positively impacting therapeutic alliance. Clinical Psychology Review, 23(1), 1-33.

Anderson, T., Ogles, B. M., Patterson, C. L., Lambert, M. J., \& Vermeersch, D. A. (2009). Therapist effects: Facilitative interpersonal skills as a predictor of therapist success. Journal of Clinical Psychology, 65, 755-768.

Baldwin, S. A., Wampold, B. E., \& Imel, Z. E. (2007). Untangling the alliance-outcome correlation: Exploring the relative importance of therapist and patient variability in the alliance. Journal of Consulting and Clinical Psychology, 75, 842-852.

Bhargava, S., \& Sriram, S. (2016). Counsellor characteristics and the counselling experience. S. Sriram (ed.). Counselling in India. Singapore: Springer Science Business.

Bruffaerts, R., Mortier, P., Kiekens, G., Auerbach, R. P., Cuijpers, P., Demyttenaere, K., Green, J. G., Nock, M. K., \& Kessler, R. C. (2018). Mental health problems in college freshmen: Prevelance and academic functioning. Journal of Affective Disorders, 225, 97-103.

Corey, G. (2009). Theory and practice of counselling and psychotherapy. USA: Thomson Brooke/Cole.

Cosci, F., Guidi, J., Mansueto, G., \& Fava, G. A. (2020). Psychotherapy in recurrent depression: efficacy, pitfalls, and recommendations. Expert Review of Neurotherapeutics, 20(11), 1169-1175.

Delgadillo, J., Branson, A., Kellett, S., Myles-Hooton, P., Hardy, G. E., \& Shafran, R. (2020). Therapist personality traits as predictors of psychological treatment outcomes. Psychotherapy Research, 30(7), 857-870.

Duncan, B., Miller, S. D., Hubble, M., \& Wampold, B. E. (Eds.). (2010). The heart and soul of change: Delivering what works (2nd ed.). Washington DC: American Psychological Association.

Eisenberg, D., Golberstein, E., Hunt, J. B., Eisenberg, D., Golberstein, E., \& Hunt, J. B. (2009). Mental Health and Academic Success in College. The B. E. Journal of Economic Analysis \& Policy Contributions College, 9(1), 1-35.

Eisenberg, D., Golberstein, E., \& Gollust, S. E. (2007). Help-seeking and access to mental health care in a university student population. Medical Care, 45, 594-601.

Eisenberg, D., Hunt, J., Speer, N., \& Zivin, K. (2011). Mental health service utilization among college students in the United States. Journal of Nervous and Mental Disease, 199(5), 301-308.

Furr, S. R., Westefeld, J. S., McConnell, G. N., \& Jenkins, J. M. (2001). Suicide and depression among college students: A decade later. Professional Psychology: Research and Practice, 27, 97- 100.

Gladding, S. T. (2016). Characteristics of Effective Counsellors Internationally (Plenary Session). Irish Association for Counselling and Psychotherapy Conference, Dublin, Ireland

Hartley, M. T. (2010). Increasing resilience: strategies for reducing dropout rates for college students with psychiatric disabilities. Am. J. Psychol. Rehabil. 13, 295-315. 
Kessler, R. C., Foster, C. L., Saunders, W. B., Stang, P. E. (1995). Social consequences of psychiatric disorders, I: educational attainment. America Journal of Psychiatry, 152, 1026-1032.

Kim, D. M., Wampold, B. E., \& Bolt, D. M. (2006). Therapist effects in psychotherapy: A random effects modeling of the NIMH TDCRP data. Psychotherapy Research, 16, 161-172.

Kosidou, K., Dalman, C., Fredlund, P., Lee, B. K., Galanti, R., Isacsson, G., Magnusson, C., (2014). School performance and the risk of suicide attempts in young adults: a longitudinal population-based study. Psychol. Med. 44, 1235-1243.

Lambert, M. J., Harmon, C., Slade, K., Whipple, J. L., \& Hawkins, E. J. (2005). Providing feedback to psychotherapists on their patients' progress: Clinical results and practice suggestions. Journal of Clinical Psychology, 61, 165-174.

Larsen, L., Christoffersen, M., \& Vedel, A. (2020). Psychotherapy Improves the Well-Being of Elderly Danish Care Recipients. GeroPsych, 33(2), 67-76.

Lohan, A., Cao, Y., Petch, J., Murray, J. and Howe, E. (2021). Does Relationship Counselling for One Work? An Effectiveness Study of Routine Relationship Counselling Services Where Only One Individual Attends. Australia New Zealand Journal of Family Therapy, 42, 320335.

McKay, K. M., Imel, Z. E., \& Wampold, B. E. (2006). Psychiatrist effects in the psychopharmacological treatment of depression. Journal of Affective Disorders, 16, 236-242.

Mowbray, C. T., Mandiberg, J. M., Stein, C. H., Kopels, S., Curlin, C., Megivern, D., \& Lett, R. (2006). Campus mental health services: Recommendations for change. American Journal of Orthopsychiatry, 76(2), 226-237.

Nen, S., \& Ibrahim, K. A. (2018). Persepsi pelajar terhadap perkhidmatan kaunseling di Universiti Kebangsaan Malaysia. Journal of Social Sciences and Humanities, 15(4), 93103.

Norcross, J. C., \& Lambert, M. J. (2011). Psychotherapy relationships that work II. Psychotherapy, 48, 4-8.

Pope, V. T., \& Kline, W. B. (1999). The personal characteristics of effective counsellors: What 10 experts think. Psychological Reports, 84, 1339-1344.

Råbu, M., \& Moltu, C. (2021). People engaging each other: a dual-perspective study of interpersonal processes in useful therapy. Journal of Contemporary Psychotherapy, 51(1), 67-75.

Sackett, C., Lawson, G., \& Burge, P. L. (2012). Meaningful experiences in the counselling. The Professional Counsellor, 2(3), 208-225.

Wampold, B. E. (2001). The great psychotherapy debate: Model, methods, and findings. Mahwah, NJ: Lawrence Erlbaum Associates.

Wampold, B. E. (2006). What should be validated? The psychotherapist. In J. C. Norcross, L. E. Beutler \& R. F. Levant (Eds.), Evidence-based practices in mental Health: Debate and dialogue on the fundamental questions (pp. 200-208). Washington, DC: American Psychological Association.

Wampold, B. E. (2010). The basic of psychotherapy: An introduction to theory and practice. Washington DC: American Psychological Association.

Wampold, B. E. (2007). Qualities and actions of effective therapists. American Psychological Association. 